\title{
“ASSESSMENT OF DIFFERENT TEACHING AIDS AND TEACHING METHODS FOR THE BETTER PERCEPTION OF BIOCHEMISTRY BY $1^{\text {ST }}$ MBBS STUDENTS"
}

Priyadarshini. K. S, H. V. Shetty, Reena. R.

1. Associate Professor, Department of Biochemistry, Rajarajeshwari Medical College, Bangalore. Karnataka.

2. Professor \& HOD, Department of Biochemistry, Rajarajeshwari Medical College, Bangalore. Karnataka.

3. II Year Post Graduate, Department of Biochemistry, Rajarajeshwari Medical College, Bangalore. Karnataka

\section{CORRESPONDING AUTHOR}

Dr. Priyadarshini K.S.

Associate Professor,

Department of Biochemistry,

Rajarajeshwari Medical College,

Kambipura, Mysore Road, Bangalore

E-mail: drpriyabio@gmail.com

Ph: 00919449270223.

ABSTRACT: BACKGROUND: Medical students during their first year of MBBS course, find Biochemistry difficult and volatile. In this regard, we studied the feedback from students about the effectiveness of prevailing teaching aids and methods, so that best teaching aid and method can be adopted to improve their academic performance. METHODS: This study comprises of total 117 students of 1st MBBS course, who have completed the 2nd semester of academic year 2011-12. Irrespective of the teacher and topic, the students were asked to grade the teaching aids and methods that were used to teach Biochemistry for the period of 10 months (from August 2011 to May 2012). RESULTS: In our study high Satisfaction Index (SI) was noticed for combination method of teaching aid (blackboard+ PowerPoint*(PPT)) and teaching preceded and followed by asking questions + assessment + tutorials, teaching method. CONCLUSION: This observation may probably be due to the fact that, inherent deficiency of each teaching aid is compensated by the other. With regard to teaching method, the combination of teaching methods is more effective when compared to didactic lectures.

KEY WORDS: Satisfaction index, Teaching aids, Teaching methods.

INTRODUCTION: Biochemistry is an essential component of medical curriculum worldwide. During initial years, the Biochemistry course consisted of teaching organic chemistry of substances of physiological importance, nutrition, metabolism and hormones. Later clinical biochemistry, genetics and molecular biology were introduced. Now most of the organic chemistry content has been removed and greater emphasis is placed on clinical correlations.

Use of teaching aids in medical education technology is swiftly changing from blackboard to virtual simulations and teaching methods range from lectures to integrated teaching.(1)

Medical students during their first year of MBBS course, find Biochemistry as difficult and volatile subject.

In this regard, we intend to study the feedback from students about the effectiveness of prevailing teaching aids and methods, so that best teaching aid and method can be adopted by teachers to improve the academic performance of the students and to make learning more interesting and effective. 
MATERIAL ANDMETHODS: The study was conducted in the Department of Biochemistry, of a Medical college with study comprising of 117 1st MBBS students who have recently completed their 2nd semester.

Teaching-aids used in study were

1. Black board alone

2. OHP (Over Head Projector) alone

3. Power Point presentation (PPT) alone

4. Over Head Projector (OHP) + Black board

5. PowerPoint presentation (PPT) + Black board

Irrespective of the teacher and topic, the students were asked to grade the above mentioned teaching aids as below.

A grade: most helpful to understand, remember and reproduce.

B grade: more helpful to understand, remember and reproduce.

$C$ grade: helpful to understand, remember and reproduce.

D grade: not helpful to understand, remember and reproduce.

E grade: not at all effective

Further the students were asked to grade the following teaching methods

1. Teaching followed by assessment/test

2. Teaching followed by tutorials (small group discussion by the teacher)

3. Teaching preceded and followed by asking questions

4. Teaching preceded and followed by asking questions + assessment + small group discussions

5. Teaching followed by self study/group study.

Students were given option to suggest any other teaching method which would improve their academic performance. After obtaining informed consent, the students were encouraged to furnish their unbiased independent opinion regarding the above study.

The response obtained from the students was statistically treated to calculate the high Satisfaction Index (SI) for Teaching aids and Teaching methods separately. (1)

RESULTS: The following bar diagram shows the opinion of 1st MBBS students towards the various Teaching aids used for conducting biochemistry Theory classes. 
ORIGINAL ARTICLE

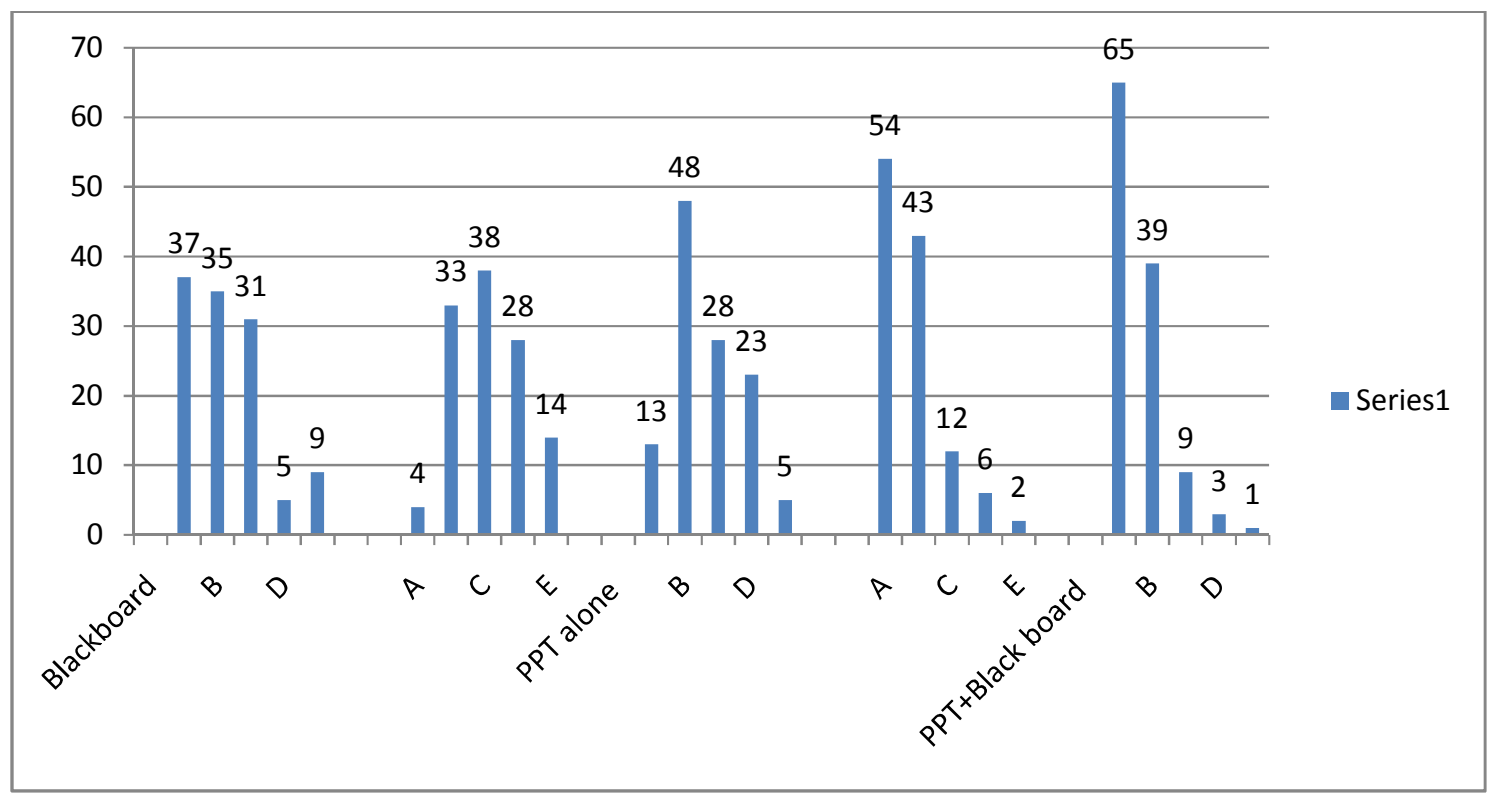

Fig 1: Graph showing opinion of 1st MBBS students towards the various teaching aids used for conducting Biochemistry theory classes. (X-axis= teaching aids and Y-axis $=$ No. of students)

Power point presentation in combination with Blackboard (66\%) was the most helpful teaching aid to understand, remember and reproduce; followed by combination of OHP and blackboard( $46 \%)$

So in our study high satisfaction index was noticed for blackboard + PPT teaching aid.

When teaching aids were individually considered, surprisingly blackboard (31\%) was preferred (A grade) over OHP (11\%) and Power point $(3.4 \%)$ the newer Teaching aids. The following bar diagram No.2 shows the opinion of 1st MBBS students towards the various teaching methods used for conducting Biochemistry Theory classes. 


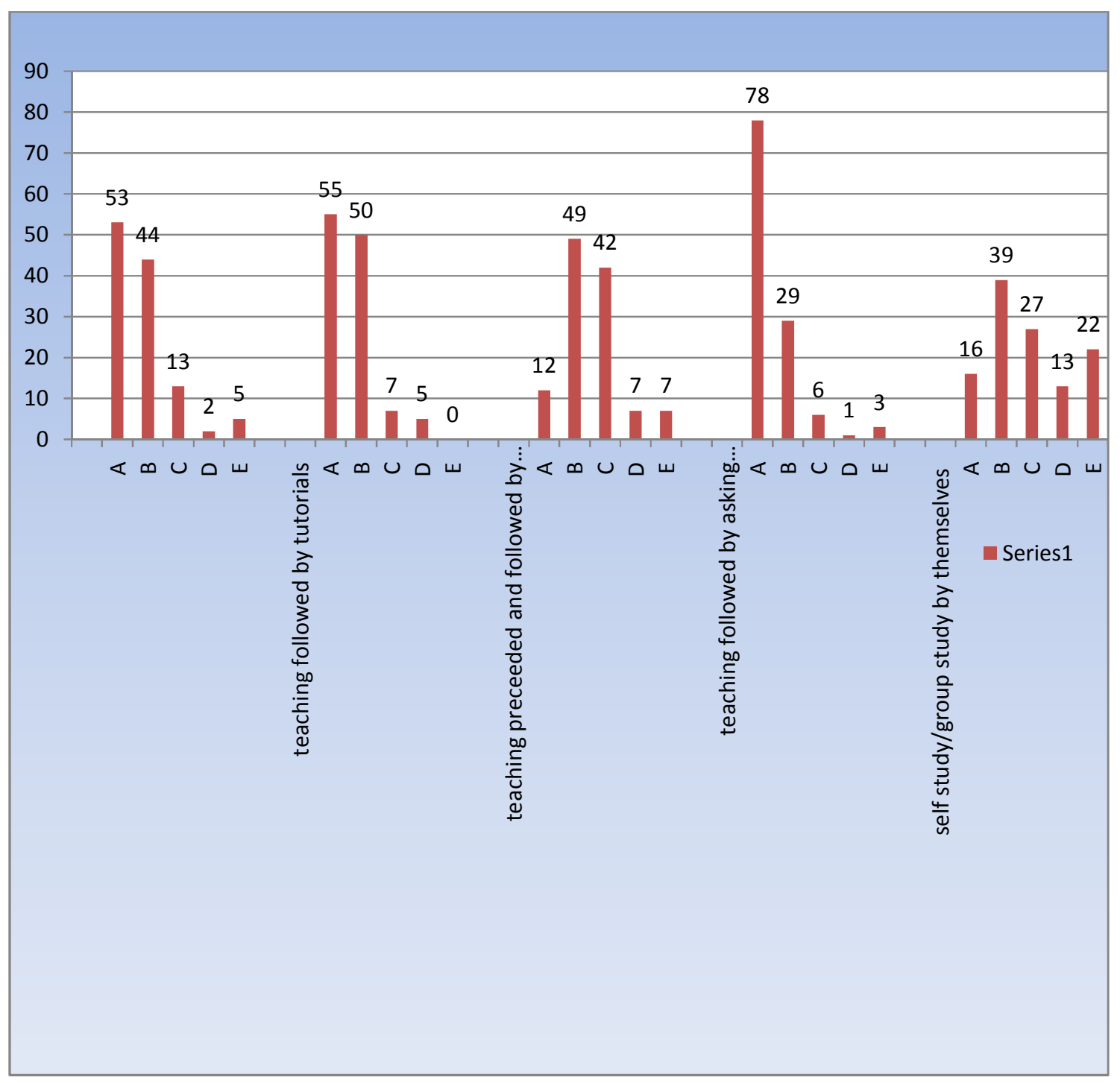

Fig.2: Graph showing opinion of 1st MBBS students towards the various teaching methods used for teaching Biochemistry theory classes. (X-axis= teaching methods and Y-axis =No. of students)

The above graph shows that teaching preceded and followed by asking questions + assessment + small group discussion (66.6\%) was considered as the most helpful teaching method to understand, remember and reproduce (A grade) when compared to teaching followed by tutorials (47\%), teaching followed by assessment/test (45\%), teaching followed by self study / group study (13\%) and teaching preceded and followed by asking questions $(10.7 \%)$.

So in our study high Satisfaction Index (SI) noticed for teaching preceded and followed by asking questions + assessment+ tutorials (66.6\%) teaching method 5 .

Suggestions/opinions given by the students on different Teaching aids and Teaching methods are :

1. Few students opine that exclusive Power Point Presentations are irritable because the lecture hall will be converted to dark Hot Air Oven and they cannot concentrate on the lecture. 
2. Video Presentations to be used as and when required.

3. Seminar Presentations will be helpful.

DISCUSSION: Teaching is an art. By making use of best teaching aid, teacher can teach and make the students understand, remember and reproduce well; thus improving the academic performance of students.

Different technologies are becoming ubiquitous in classrooms. The use of better teaching aid allows the students to understand the metabolic pathways, cycles, flowcharts, structures and diagrams better. This also allows more time for interaction and further understanding. Use of technology can be a very beneficial and time saving tool for all teachers.

An evaluation by the students can provide the teacher with useful feedback information regarding the best Teaching aid and Teaching method.

In our study, students preferred combination of teaching aids rather than individual teaching aid. Among the two prevailing combination teaching methods, majority of the students have opted PPT + Black board as their preferred aid for the better perception of subject.

This observation may probably be due to the fact that, inherent deficiency of each method is compensated by the other. While blackboard teaching is deficient in showing three dimensional diagrams, animated videos and sounds; the same can be demonstrated using a Power Point presentation. Power Point presentations take less time to present the same information as compared to Black Board teaching. Blackboard teaching allows the students to take down the notes and diagrams which is difficult with Power Point presentations as there is tendency to deliver the lecture fast (2).

Our study can be compared with the study done by Chaudhary R (2009). In their study also majority of the students (67.1\%) favored the combination of teaching aids. The drawback which the students pointed in Black Board teaching, is that it takes time to draw a labeled diagram on the board and during that time teacher's eye contact with the students is interrupted.(3)

Roopa kulkarni (2011) and co-workers in their study, have also concluded that audiovisual aids enhance the effectiveness of the Blackboard Teaching. (4) A Garg (2004) have taken the students opinions on the prevailing Teaching methods in Pharmacology and showed that $81 \%$ of the students wanted the teacher to make use of audio visual aids during the lectures.

If we consider the individual teaching aids that is not in combination, Blackboard Teaching was opined as most helpful to understand, remember and reproduce (A grade) teaching aid. Teaching using OHP alone and PPT alone was opined not effective at all.

The points which favour Chalk and Talk method are :

1. The rooms will be illuminated

2. Teacher can hold the attention of students and students can cope with the speed of the teacher

3. It increases the ability of the students to think and understand the contents and simultaneously take down the notes and write the diagrams. 
4. Student teacher interaction will be better

5. No interruption because of power failure.

S. N. Baxi (2009) in their study showed that an equal number of students preferred Blackboard based or multimedia-based lectures. (6)

In few studies like Seth (2010) who have compared the preference for teaching aid between medical students versus dental students. The medical students have preferred PPT whereas the dental students preferred the Chalkboard. (7)

TEACHING METHODS: Now $1^{\text {st }}$ MBBS duration has reduced from $1 \frac{1}{2}$ years to 1 year. This duration should be effectively used to get best outcome from the students. In this view we assessed best teaching methods for best perception by the students.

The results from the cognitive sciences provide insights into the neurological basis of memory formation and learning. Learning involves three steps: acquisition of information (physical encoding in the brain), its retention and the ability to retrieve the information when needed. (8)

We found that teaching preceded and followed by asking questions + small group discussions + assessment/tests (in the form of MCQs or essay type questions - chapter wise) was opined as best teaching method by the students.

This observation may be due to; asking of questions of previous lecture would make the students to read and come for ongoing lecture and it acts as bridge for the next concepts. Asking questions in between and after the class will keep the students to be attentive throughout ongoing lecture and also it breaks the monotony; an inherent component of didactic lectures. A discussion will allow students to clear their queries. The unit tests are helpful as they allow students to study the limited portion of syllabus thoroughly and also to learn writing techniques and time management skills.

Our study results also support the concept of multiple intelligences in learning identified by Gardner and Kolb’s Experimental Learning Cycle theory of learning. (8)

In a study done by Roopa kulkarni (2011), their students opined that questioning in the class room is not only helpful for better understanding of the concept but also helps in developing communication skills. In the same study, $67 \%$ of the students wanted mixture of lectures and small group Teaching. (4)

CONCLUSION: Combination Teaching aid is most satisfied Teaching aid because the inherent deficiency of one aid is compensated by the other. If individual teaching aids are considered Blackboard teaching aid is most satisfied because students can follow the teaching and understand the concept effectively.

Combination of teaching preceded and followed by asking questions + small group discussions + assessment/tests is most satisfied teaching method because the student is actively involved and more learning takes place. Judicious use of different methods increases the understanding, remembrance and reproducibility and thus the academic performance of the 
student.

\section{ACKNOWLEDGEMENTS:}

1. 1st year MBBS students (Batch 2011), RRMCH, Bangalore-40.

2. Dr. Vittal BG, Associate Professor of Biochemistry, BIMS, Bidar, Karnataka, Pin-585 401.

3. Dr. Chandrika, Assistant Professor of Biochemistry, RRMCH, Bangalore-40.

\section{REFERENCES:}

1. KaushikBhowmick, MousumiMukhopadhyay, SandipChakraborty, Pradyut K Sen, Indrani Chakraborty.2009. "Assessment of perception of first professional MBBS students in India about a teaching learning activity in Biochemistry" South East Asian Journal of Medical Education, Vol. 3number2,27-34.

2. Vikas Seth1, Prerna Upadhyaya1, Mushtaq Ahmad1, Virendra Kumar.2010.“Impact of Various Lecture Delivery MethodsInPharmacology".EXCLI Journal; 9:96-101 - ISSN 1611-2156 3. chaudry R, Dullo P, Gupta U. 2009. "Attitude of 1st MBBS medical students about two different visual aids in physilologylectures".Pak Journal Physiology; 5 (2). 4. Roopakulkarni, Ashwini. C A, Bharath Reddy.2011. "Student Perception on Lectures in Medical Education. Anatomica Karnataka, Vol-5, (2) 01-13. 5. A Garg, PV Rataboli, K Muchandi. 2004. "Students opinion on the prevailing teaching methods in pharmacology and changes recommended. Indian Journal of Pharmacology. 36: 3, 155-158. 6. S N Baxi, C J Shah,R D Parmar,Parmar,C B Tripathi.2009.“Students' perception of different teaching aids in a medical college"AJHPE.Vol. 1, No. 1, 15-16. 7. Vikas Seth, PrernaUpadhyaya, MushtaqAhmad,Vijay Moghe.2010."PowerPoint or chalk and talk: Perceptions of medical students versus dental students in a medical college in India". Advances in Medical Education and Practice.1 11-16.

8. Andy C Reese, PhD. 1998. "Implications of results from cognitive science research for medical education".Medical education online. 3,1.http://www.utmb.edu/meo/ 9. AlexandreB.Se, Renato M. Passos, Andre H. Ono and Marcelo Hermes-Lima. 2007. "The use of multiple tools for teaching medical Biochemistry". AdvPhysiol Educ. 32:38-46. 10. Heidi L. Lujan and Stephen E. DiCarlo.2006.First-year medical students prefer multiple learning styles.Adv/PhysiolEduc

30:13-16.

Microsoft PowerPoint is the name of a proprietary commercial software presentation program developed

by Microsoft.

Only the curious will learn and only the resolute will overcome the obstacles to learning. The quest quotient has always excited me more than the intelligence quotient. Eugene S. Wilson 